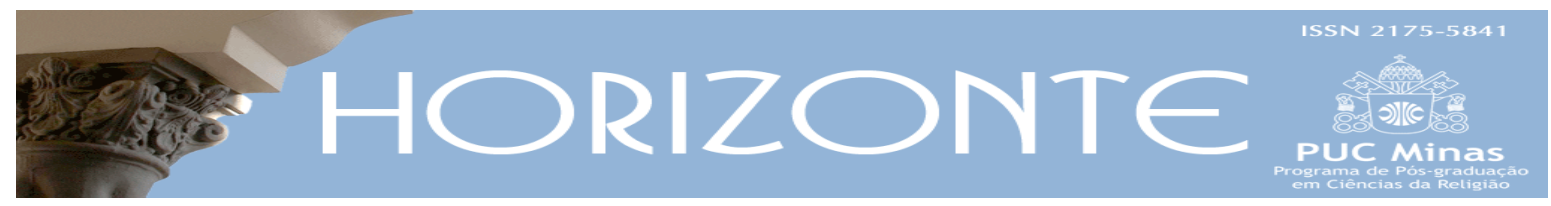

Temática Livre - Artigo Original

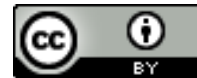

DOI - 10.5752/P.2175-5841.2017v15n47p887

\title{
Leitura bioética de variações sociais da vigilância em condomínios
}

Bioethics reading of variations in social Surveillance in condominiums

\author{
Márcio Fabri dos Anjos* \\ Rogério Jolins Martins**
}

\begin{abstract}
Resumo
O objetivo do artigo é pensar a bioética nas variações sociais da vigilância em condomínios. A vigilância é ambivalente no seu conceito e em suas práticas e serve tanto para proteger quanto para dominar. Este é um estudo conceitual bibliográfico que, inicialmente, descreve a passagem do sentido de cuidar para uma relação de domínio, seguida por algumas experiências de variações socioculturais de vigilância; um terceiro passo aborda as regras da vigilância que garantem a coesão nos condomínios; e, por fim, faz-se uma leitura bioética dos processos de vigiar. A bioética questiona o modelo atual de vigilância que tenta salvaguardar a segurança de um grupo, dentro de uma sociedade composta por violências, mas que não atende toda a coletividade. Por isso, tal modelo se mostra insuficiente para garantir uma segurança efetiva que se busca. Propõe, no entanto, que se busque um ambiente seguro no qual a segurança e a liberdade estejam em equilíbrio.
\end{abstract}

Palavras-chave: Bioética. Segurança. Condomínios. Privacidade.

\begin{abstract}
The purpose of this article is to think bioethics in the social variations of surveillance in condominiums. The surveillance is ambivalent in its concept and in its practices, and serves both to protect and to dominate. This is a concept study of literature which, at first, describes the change from a way of caring into a dominance relationship, followed by some experiences of variations in sociocultural surveillance. A third step deals with the rules of surveillance which ensure cohesion in the condominiums. And, finally, a bioethics reading of the processes of watching. Bioethics questions the current model of surveillance that attempts to protect the safety of a group, within a society composed of violence, but that does not serve the community as a whole. As a matter of fact, such a model proves insufficient to ensure effective security. Therefore, the study proposes to seek a safe and secure environment in which security and freedom are in balance.
\end{abstract}

Keywords: Bioethics. Security. Condominiums. Privacy.

\footnotetext{
Artigo submetido em 25 de maio de 2016 e aprovado em 23 de agosto de 2017.

* Doutor em Teologia pela Pontifícia Universidade Gregoriana, em Roma. Licenciado em Filosofia. Coordenador do programa de doutorado e mestrado em Bioética, do Centro Universitário São Camilo, São Paulo. Presidente da SOTER-Sociedade de Teologia e Ciências da Religião (1991-1998). País de Origem: Brasil. E-mail: mfabri@terra.com.br

** Doutor e Mestre em Bioética pelo Centro Universitário São Camilo/SP. Possui graduação em Filosofia pela PUC/MG (1998), graduação em Teologia pela PUC / SP (2007). Professor de Filosofia com ênfase em Antropologia, Ética e Bioética na Pontifícia Universidade Católica de Minas Gerais - PUC Minas. País de Origem: Brasil. E-mail: rjolinsmartins@gmail.com
}

Horizonte, Belo Horizonte, v. 15, n. 47, p. 887-904, jul./set. 2017 - ISSN 2175-5841 


\section{Introdução}

O condomínio sob o ponto de vista ético é uma caixa de múltiplas surpresas. $\mathrm{Na}$ sua raiz está o domínio; na raiz do domínio está o exercício do poder na complexa área das relações humanas; na necessidade do exercício do poder está a fragilidade que expõe o ser à vulnerabilidade em seus ambientes. Esta cadeia de pressupostos sugere que os fundamentos éticos do condomínio têm uma base profunda na constituição do ser humano e nas formas concretas que tomam o ambiente de seu existir e se relacionar. A necessidade de vigilância é uma derivação deste conjunto.

A presente aproximação conceitual e bibiográfica sobre a ética nas variações sociais da vigilância em condomínios de modo geral, foi provocada pelo interesse em um estudo bioético focalizado sobre condomínios horizontais, de classe média em um centro urbano brasileiro, estudo esse que é não relatado aqui. Mas sua menção sugere a relevância dos fundamentos bioéticos que se tornam úteis para avaliar as diferentes situações de vigilância na atualidade. De fato, para entender adequadamente a ética da vigilância aguçada pela eficiência tecnológica de nossos tempos parece necessário situá-la em uma reflexão de âmbito sociocultural mais amplo. A história da vigilância é naturalmente um importante espaço de elucidação a ser considerado. Com os enfoques bioéticos no tema, abrimos mão de uma leitura histórico-evolutiva para colher aspectos que elucidam as variações socioculturais que afetam os sentidos éticos da vigilância. Esta opção parece se adequar melhor à busca das dimensões éticas em meio às variações das formas culturais que plasmam a vigilância através dos tempos, entre as quais se situam os atuais condomínios urbanos.

\section{A Vigilância: do Cuidado ao Domínio}

A vigilância nasce da experiência humana quanto à sua fragilidade frente ao outro no seu ambiente. Sua necessidade e as formas com que esta se constrói 
dependem do quanto se percebe ameaçado em seu ambiente e nas situações de violências à qual o ser humano está exposto. Essa condição vulnerável o faz recorrer a formas e estratégias de se proteger. Além do autocuidado, as formas coletivas de cuidado mútuo constituem uma prática condizente à sua condição imemorial. Estas formas de vida se encontram de modo facilmente perceptível entre os animais em geral, na organização de bandos e sistemas de alerta diante das ameaças; e até nas formas de vida vegetal seria possível detectar sistemas análogos do mútuo cuidado, enquanto, por exemplo, uma floresta significa potencialização do seu ambiente favorável à vegetação. A luta pela sobrevivência das espécies e não simplesmente de indivíduos, como propôs Darwin (DARWIN, 2003, p. 468), dá lugar ao suposto de um sistema de união grupal.

A impossibilidade de uma constante autovigilância gera a necessidade do cuidado compartilhado nos diferentes grupos de convivência. Para além do instinto, a vigilância, como cuidado, é uma característica ética fundamental que os seres humanos assumem como proteção e defesa. Um ambiente de sólido compromisso comunitário estabelece a vigilância como cuidado mútuo; em outros termos nota Vázquez que os vínculos comunitários são a garantia de sistemas éticos de vigilância pela defesa e sobrevivência do grupo (VÁZQUEZ, 1978, p. 39). Mas suas considerações sugerem que a passagem dos bens e propriedades da esfera comunitária para subgrupos e indivíduos, ao fragmentar os vínculos comunitários, multiplica internamente as áreas de ameaça e de violência na disputa pelos bens e pela força de produção laboral.

As possíveis situações de ameaças e hostilidades nas experiências grupais e intergrupais fazem o ser humano abandonar a vigilância na sua condição de cuidado para assumi-la na sua conotação de domínio. Leva-o a empreender meios para sua proteção, e empenhar-se em montar torre de guardas para manter-se à espreita. Ao mesmo tempo em que ele se mostra dependente, manifesta-se também nas suas relações de forças, estabelecendo um conflito permanente que faz a vigilância nas relações condominiais terem diferentes sentidos. 
Dessa polivalência emerge o conflito interno e externo que provoca nos seres humanos o medo como um ponto cego constitutivo de sua insegurança, que os faz almejar por forças que aplaquem seus possíveis rivais. Neste sentido, a vigilância é em si mesma ambivalente. Ao mesmo tempo em que precisa de determinadas formas de defesa, deve atentar para as formas de defesa e vigilância do outro que podem no fundo significar ameaças. Essa sensação desperta desconfiança nas relações e assimetrias nas relações de poder, uma vez que o outro grupo é visto como um potencial concorrente e não um parceiro nos sistemas de defesas grupais. Nesta lógica, tenta-se agir antes que o outro o faça. Essa inversão nevrálgica sugere a compreensão da vigilância entre os extremos, num descompasso de ações que vão desde o seu objetivo primeiro que é o cuidado, passando por um estado de incerteza, até chegar a uma explícita relação de domínio, a depender da intencionalidade que se tomam nas relações.

Nessa linha de compreensão Fuchs afirma que é bom assumir de uma vez por todas a não neutralidade da vigilância, ou sua teorização negativa, porque dela decorre no fundo uma relação de poder (Fuchs, 2011, 109-136). Ao mesmo tempo em que ela é uma necessidade para proteção, constitui também um risco. Essa ambivalência da vigilância está bem fundamentada por Foucault em seu clássico estudo sobre os sistemas disciplinares e coercitivos que levam o homem à submissão, ao construir regimes de poder e elaborar discurso sobre a verdade (Foucault, 2011, 155).

Da necessidade de vigilância inerente à condição humana de ser limitado, também outros pensadores, como Deleuze (1992, p. 219-226), apontam a vigilância como possibilidade de se tornar dispositivo de controle e ferramentas que permitem a manipulação de indivíduos e grupos sociais, com interesse de supervisioná-los. A vigilância que, inicialmente, está para proteger um grupo contra a violência, torna-se ela mesma um tipo de violência interna dentro do grupo, através do controle e submissão de seus membros, reproduzindo assim de certa forma a violência contra a qual visaria defender. 


\section{Variações socioculturais da vigilância}

Os indivíduos e as sociedades sempre se mobilizaram no sentido de se defenderem de incômodos e de possíveis ações que lhes ofereçam riscos. Desde as primeiras experiências de convivência, as disputas se acirraram entre os próprios membros dos grupos que, para se defenderem buscam organizar as relações internas do grupo, ou estabelecer sistemas de alianças em torno de interesses similares; chegam deste modo com grande frequência à organização de grupos dentro do grupo maior, pela atribuição de diferentes tarefas e em troca de alguns benefícios. Este fenômeno, segundo Larrère (2011) se encontra em e entre grupos humanos e não humanos.

Como bem ilustra o estudo de Marquese (2006) com referência à dinâmica da escravidão no Brasil, as disputas por domínios dentro das sociedades, tomam diferentes cores pela mudança utilitária das práticas morais que passa do costume de matar o inimigo capturado nos conflitos armados, para tomá-lo como mão de obra escrava. Mas a propriedade, a produtividade, a mão de obra escrava e livre despertam o espírito de autoproteção por parte dos proprietários, que reinventam formas de manter a supremacia nessas disputas.

As cidades marcam espaços para onde indivíduos migraram no sentido de se protegerem. Estas, no entanto, se tornaram formas de organização condominial com conflitos e disputas veladas entre seus habitantes, e bastante espelhadas nas diferenças entre centros sociais urbanos e comunidades de periferias sociais rotuladas como favelas. Não se trata aqui de discorrer sobre a origem da cidade, mas de explorar nela seus sistemas de domínio e vigilância. Lyon, respeitado internacionalmente por seus estudos sobre vigilância, ressalta na origem das cidades, além de seu favorecimento aos interesses comerciários de estoque, venda e consumo dos produtos agrícolas, também as vantagens de uma defesa coletiva dos bens, garantida por uma vigilância em sistema urbano (Lyon, 2007, p. 12). 
Esta ingerência do domínio de bens sobre a vigilância aparece implícita na crítica de Rousseau ao mito da propriedade privada na fundação da sociedade civil (Rousseau, 2005, p. 203). O domínio da propriedade sobre a vigilância é sentido, conforme relata Veyne, nas particularidades culturais de alguns "condomínios" sob influência do Império Romano na antiguidade (Veyne, 2009, p. 17-211). A vida condominial era privada e estava muito ligada à casa. A vigilância era importante, pois um senhor tinha dezenas de escravos dentro de sua moradia. O dono ou a dona da casa encarregavam os escravos de confiança de espionar a conduta de outros escravos, dos "amigos", dos preceptores e outros domésticos de condição livre: os escravos cochichavam ao ouvido do dono tanto os ridículos como os escandalosos segredos da casa.

Pela domus romana se dava uma delimitação do espaço entre a elite e a plebe. Essa divisão entre classes sociais era manifestada nas habitações entre os senhores e a plebe. Os primeiros tinham o dever de proteger seus súditos nos espaços internos de suas fortalezas. Os súditos, por sua vez, pagavam seus senhores com o trabalho e com impostos para que os mesmos mantivessem suas cortes. Trata-se de um sistema que delimitava quem eram os "de dentro" e quem eram os "de fora", sendo os "de fora", os estranhos, supostamente os inimigos.

Mais do que sinais externos para caracterizarem as divisões sociais, essas já eram antecipadas pela divisão de nascimento (Veyne, 2009, p. 17-211). Ou seja, o lugar do nascimento determinava a qual lado do muro pertenciam os indivíduos, e o status social de que gozavam. Com isso, a construção de uma muralha representava bem mais do que apenas a defesa contra ataques vindos de fora, ou da divisão entre camponeses e o meio urbano, entre espaço interno e externo; representava uma separação entre os propiciavam e os que usufruíam da proteção dentro do espaço murado.

Le Goff situa essas demandas como sendo os primeiros passos para a fundação de uma cidade (Le Goff, 1992, p. 25). As demandas sociais e a segurança levaram à construção daquelas que se tornaram o maior símbolo de proteção às 
cidades, devido às guerras, às invasões, à falta de mantimentos, às doenças e à organização da estrutura interna. Quaisquer que fossem as razões, as muralhas fortificadas eram importantes para proteção contra violências. Dentro dos seus portões fazia-se necessário defender a paz e proteger a ordem interna.

Dentro dessas muralhas, as divisões sociais eram evidenciadas na cadeia entre detentores de grandes e pequenas propriedades e aqueles despossuídos de bens, quando não eram escravos. Essas cidades guarnecidas tinham o poder concentrado numa só pessoa que procurava demonstrar seu domínio de forma piramidal que, para se legitimar, construía palácios, templos e outras edificações que visavam subjetivar nos súditos o distanciamento entre a grandeza de sua pessoa ou função e a obediência que lhe era devida. Em algumas culturas a estrutura imponente das edificações sinalizava as assimetrias existentes entre o rei e os súditos, a ponto destes considerá-lo uma autoridade divina.

Muito além da mera delimitação de espaço, as muralhas serviam como proteção aos que residiam na cidade. Para os moradores romanos, por exemplo, o muro era penhor de civilidade. Os muros eram os mais belos enfeites de uma cidade, porque, nesse cinturão, as pessoas se sentiam como numa domus coletiva; os espaços internos das muralhas garantiam a proteção, mas mesmo não vivendo com medo dos ladrões, preferia-se fechar os portões à noite. Em consequência, toda entrada e saída noturna era suspeita; os mal-intencionados não ousavam apresentar-se à guarda que detinha as chaves de cada porta.

A polis grega ilustra bem o esforço de conjugar na cidade os múltiplos interesses particulares e incluindo nisto dominações, como a escravatura, e discriminações étnicas e de classes sociais. Mas a cidade é parte da natureza política do ser humano, da qual este não pode dispensar. Se nas cidades se dão as experiências de conflito, nelas também se encontram o ideal da vida feliz, na convivência com os demais na prática da justiça, no respeito às leis, à segurança e à educação, bens estes assegurados pela atividade política e militar (Aristóteles, 1997, p. 53). 
A prática do bem na polis deveria assegurar um ambiente saudável, sem catástrofes, seguro, em que a vigilância tanto individual quanto comunitária deveriam ser consideradas, pois se a cidade atravessasse um estado de caos, o indivíduo também estaria ameaçado. Dentre os modelos de cidade, a polis grega é a que mais claramente expressa a dimensão política do urbano (Rolnik, 2004, p. 22).

Além da polis grega, outras experiências socioculturais antigas de vigilância se formaram como a egípcia, babilônica, chinesa, israelita e outras cujo objetivo era a proteção. As cidades que nelas se formaram, buscavam se instalar à beira dos rios para aproveitar as terras férteis, bem como pela maior facilidade de locomoção, o que implicava maior domínio por habitar em lugares estratégicos, mas que simultaneamente requeria maiores mecanismos de defesa. Ou seja, os canais que ofereciam expansão possibilitavam vulnerabilidades como riscos de invasão, o que demandava por equipamentos de defesa sempre mais aprimorados frente às adversidades. A oferta de vigilância se somava ao conjunto de regras morais ou legais, além de fatores culturais e religiosos, para favorecer certa unidade ou coesão no interior dos condomínios urbanos, seja pelas relações sociais ou pela hierarquia de poder assumida como condição da proteção.

Tais estratégias são articuladas para preservar as influências de indivíduos e grupos, guarnecer o poder e dificultar a presença de possíveis invasores. Mas os sinais de extrapolação ética da vigilância que se transmuta em controle são abundantes na história. Com algumas variações, e com colaborações técnicas ou científicas, os condomínios micro ou macro se serviram de outras formas de vigilância para os mesmos objetivos. Dentre alguns desses condomínios estão família, igrejas, mosteiros, escolas, hospitais, fábricas, comércios, associações, partidos políticos, grupos de tráfico, corporações profissionais, instituições vinculadas aos Estados, empresas, grupos formados por redes digitais, e semelhantes.

Segundo Rolnik (2004, p. 41), em tempos modernos, as cidades se tornaram um mosaico de condomínios socialmente separados, nas quais é fácil identificar 
territórios diferenciados, onde num lugar ficam as mansões ou áreas nobres, em outro fica o centro comercial-empresarial, em outro fica a zona boêmia, em outro fica a zona industrial, em outro fica a favela. A cidade é toda mapeada. É como se houvesse cercas demarcando, como fronteiras imaginárias, o lugar de cada coisa para cada morador. Esse espaço segregado evita o que é notável nas grandes cidades, em que entre os prédios envidraçados e gestos tensos dos homens de terno e pastas de executivo, não se cruzam com outras realidades totalmente deslocadas do modo de vida destes.

As cidades, de lugar de encontro, acabaram se tomando com muita frequência características de local de desencontro, com batalhas e hostilidades entre "inimigos morais", ou contra os forasteiros que geram insegurança, justificando com isso mecanismos de vigilância que garanta segurança. Da presença do estranho, que por si só amedronta, passou-se ao estigma àqueles que devem ser rejeitados, pois vivem o tempo todo em espaços subjetivados pela violência. O raciocínio recorrente é que a violência provoca danos e, por isso, deve ser rejeitada, mas, sobretudo, devem ser rejeitados aqueles que explicitamente a provocam.

As muralhas de concreto persistem, mas, nos dias atuais, elas têm pouco efeito para apartar os indivíduos que vivem dentro e fora delas. Com isso, fez-se necessário criar novas muralhas, entre as quais estão os sofisticados e eficientes equipamentos de vigilância, com a organização de novas regras e novos modos de administração que consigam proteger-se das situações de violência, e fortalecer as próprias condições de poder.

\section{Sobre as regras da vigilância nos condomínios}

As regras são um importante elemento para garantir o ordenamento social nas cidades. Platão dizia que nas cidades, a figura do guardião seria fundamental para dirimir conflitos, supervisionar incisivamente a educação das crianças, 
moldando sua natureza e norteando-as sempre para o bem prescrito pelas leis (Platão, 1999, p. 302). A organização da mesma estava em ir de encontro às necessidades de um habitat seguro, e garantir a satisfação humana nas relações intracondominiais/intercondominiais.

O empecilho na construção da cidade virtuosa estaria nos vícios que impediriam as cidades de serem organizadas, apontando como o maior deles, a injustiça (Platão, 1997). A desobediência às virtudes incorre na punição, cuja qual as normas lhe subsidia para garantir o domínio. A tática é controlar a sociedade, e para isso faz-se necessário punir publicamente, como técnica de inibição social, os indivíduos que cometem desvios. Para o controle, a regra tem um grande contributo.

As regras deveriam ser feitas pelos guardiães/magistrados capazes de garantir a harmonia nos espaços internos, e, teoricamente, todos deveriam acatálas, inclusive seus administradores. As regras que são para os habitantes da cidade servem, sobretudo, para os de fora e delimitar os espaços entre os de dentro e os considerados estrangeiros. Sem autorização, aqueles que estão fora devem ser impedidos de entrar; o mesmo não vale para os de dentro.

Esta é a mesma compreensão dos condomínios urbanos contemporâneos nos quais há regras e hierarquia administrativa. As regras objetivam garantir um espaço harmonioso e, portanto, distanciadas das situações de violência, garantidas pelos gestores que são os novos guardiões da vigilância. A complexidade das variações condominiais passou a exigir um modelo de punição mais elaborado que o panoptismo proposto por Jeremy Bentham (2000), fazendo com que todos, e não somente alguns, ficassem sob a inspeção dos administradores que, por sua vez, têm o controle. Para isso, conta-se com um modelo de vigilância invisível, sinóptica ou em rede, característico da época pós-moderna.

Aos guardas são disponibilizadas as estruturas necessárias, para que tenham total controle sobre as áreas internas e garantam segurança à "comunidade moral". 
Eles assumem a função de burocratas/gestores de pessoas, devendo ser especialistas em tomar decisões baseadas em cálculos funcionais. Como administradores, podem calcular o que mais lhe convém, tendo ou não a confiança dos proprietários residentes da comunidade.

Nas práticas administrativas os gestores se mostram flexíveis, mas devem garantir a normalidade e o bom êxito da segurança aos residentes a custo da submissão e obediência de todos. Eles são legítimos representantes dos interesses de grupos fechados, mas atuam para além dos limites dos muros, sobretudo quando, com o argumento de suposto combate à violência e autodefesa, suspende a própria lei. Tal como entre Hobbes e Rousseau, a proposta de administração se situa no intercurso entre dois extremos: o da severidade totalitária ou o da flexibilidade, pela qual alguns chegam a observá-la como uma figura impessoal.

Ao mesmo tempo em que as regras propõem que todos sejam pequenos legisladores de uma micropolítica, em outros casos os residentes fazem parte de um modelo social menos politizado, no qual a vigilância é uma exigência ao ordenamento em que indivíduos participam como usuários voluntários (Boétie, 1999, p. 90) de um sistema que, de forma deliberada, rastreia e seleciona as classes sociais.

Essa despolitização constitui a negação radical da autonomia do indivíduo e do sentido de cidade enquanto polis. Numa sociedade altamente vigiada não se elegem dirigentes, nem se discutem objetivos, tampouco se reflete sobre valores e utopias. Nela reina o pragmatismo e o sentido prático; a segurança e a produtividade são as únicas coisas que importam. Para este modelo de organizar a vida, é necessário acima de tudo controlar a sociedade. A perspectiva de universalizar o discurso e as práticas de segurança está vinculada às estratégias política e econômica que vão além da organização e do aumento de produtividade. Insere-se na dinâmica mais ampla que Foucault diz tratar-se de uma prática social para construção histórica de relações de poder (Foucault, 1979, p. XXIII). Este alerta de Michel Foucault ressalta que se deva cultivar um constante olhar crítico 
sobre os sistemas de vigilância para que visem garantir a segurança e não se tornem controle sobre os indivíduos.

\section{Leitura bioética}

Refletir acerca da vigilância na bioética é chamar a atenção para um cenário complexo em que seus dispositivos se apresentam como uma necessidade em prol de segurança, mas que, também, podem ser utilizados na perspectiva de garantir o controle sobre as vidas humanas. Parece clara a complexidade da vigilância que envolve diferentes formas de conflitos físicos e morais. Ao mesmo tempo em que os indivíduos têm necessidade de proteção, no contexto de uma sociedade com recorrentes situações de violência, deve-se cuidar para que os próprios sistemas de vigilância não os subjuguem. Estes são temas sobre os quais não há mais um paradigma simplificado (Morin, 1999, p. 175), tratando-se de um assunto aberto à mediação de pareceres como as Ciências Políticas, o Direito, a Sociologia, a Psicologia, a Filosofia, devido aos problemas gerados no âmbito das práticas sociais.

A vigilância constitui-se como necessária numa sociedade violenta, sobretudo por estar enraizada nas "situações persistentes" (Garrafa; Porto, 2003, p. 35-44) das estruturas iníquas que geram miséria, opressão e reproduzem as desigualdades. A solução dessa aguda dimensão de demanda por vigilância remete ao ideal de uma ética de responsabilidade (Jonas, 2006, p. 220), que, entretanto, para se realizar supõe uma ingente transformação sociocultural. Enquanto se dão os passos em busca da ética em tal contexto de violências, é indispensável manter acesa a atenção crítica sobre os interesses que estão subjacentes à vigilância apresentada aparentemente sempre como um bem.

A complexidade com relação à vigilância, para além de ser uma necessidade, dá-se também pela incerteza de suas potencialidades e sua absorção por parte dos indivíduos, a ponto de estes a aceitarem quase como um determinismo. Pela bioética, um olhar crítico sobre tal fato leva a inserir a vigilância dentro do contexto 
maior do ser humano e suas circunstâncias, na grande rede de relações com seu ambiente, conforme foi proposto por Fritz Jahr(1927, p. 21-32); naturalmente sem esquecer o quanto ela está implementada hoje por altas tecnologias de modo geral e particularmente pelas digitais. Em nossos tempos, Van Rensselaer Potter (1988) retoma as tese de Jahr e as propõe como Bioética global. A Declaração Universal sobre Bioética e Direitos Humanos (UNESCO 2005) prossegue nessa direção explicitando um conjunto de princípios a guiar a defesa das pessoas e do ambiente, em meio às sociedades violentas em que vivemos.

Nesse quadro global de consciência ambiental e de organização ética na vida política, Bauman (2003, p. 24) defende a necessidade ética de considerar a liberdade e a segurança como necessidades humanas fundamentais. Conforme este autor, a ênfase sobre um desses tópicos, em detrimento do outro, desencadeia um desequilíbrio que pouco contribui para o processo social básico que garanta uma vivência de qualidade para ser chamada de humana (Bauman, 2013, p. 44). O fato de a vigilância ser necessária em ambiente de riscos, leva as pessoas a negociarem dimensões de sua privacidade para resguardar o que for possível, dentro do ambiente urbano de medo e insegurança. Uma interrupção desta espécie de círculo vicioso demanda um investimento na transformação do próprio ambiente global que faz da negociação uma espécie de resignação diante da violência que predomina no ambiente.

A reversão do ambiente de violência conta com um obstáculo na própria condição das pessoas que buscam a vigilância para dela se defender. Trata-se da internalização da inexorabilidade da violência na consciência moral das pessoas que já não se preocupam em pensar nas soluções estruturais. A crítica a tal processo de dominação já foi levantada por pensadores como Paulo Freire (1990) e Michel Foucault (2010). Simmel (2009, p. 219-242) observa a esse respeito que o último recôndito capaz de fazer frente ao controle é controlado, levando os indivíduos a pensar que suas decisões sejam livres e nada haja mais a ser questionado. 
Apesar da privacidade ter sido pensada desde tempos passados em seus diferentes âmbitos e sentidos, ela ganha cores particulares na modernidade que a coloca em uma correlação de forças encontrada pelo "eu" para enfrentar uma possível superioridade do "outro". Sem considerar a propriedade ou não dos termos do autor, Mattéi (2002, p. 12) considera que a "barbárie exterior", instaurando a necessidade de vigilância, produz a legitimação de uma "barbárie interior" mais profunda por invadir a interioridade das pessoas e depreciar pontos centrais de sua dignidade como seres humanos.

Prost (2009, p. 13-136) considera que, mesmo não sendo a privacidade uma realidade natural, mas construída de diversas maneiras por sociedades determinadas, ela emergiu nos meandros da vida burguesa, e ao final do século XIX houve um despertar para o seu reconhecimento; esta emergência recebeu legitimação política com a Declaração Universal do Direitos Humanos na tentativa de fazer frente à marca definida como mal do século (Corbin, 2009, p. 387 e 568), sobretudo provocada pelas formas nazistas de invasão da privacidade das pessoas; resultou que a privacidade foi assumida como princípio pelos Estados democráticos de direito. Tal princípio tem o status de inviolável, com ressalvas para casos de flagrante delito, desastre, necessidade de socorro ou por determinação judicial. As normas que garantem proteção à consciência do indivíduo, bem como a seus pensamentos, seus sentimentos e convicções se tornam de modo geral cláusula pétrea nas Cartas Magnas das nações democráticas. As práticas de vigilância, especialmente as desenvolvidas através de sistemas digitais, recolocam novos desafios e problemas quanto às garantias do respeito à privacidade das pessoas; tal situação explica porque Mattéi acima citado classifica de "barbárie" as formas modernas de invasão de privacidade.

Preservar a privacidade é uma forma de controlar o poder arbitrário do controle. Se há cerceamento da privacidade, não há como as pessoas discutirem tranquilamente os rumos de suas vidas e instituições políticas. A retirada desse direito constitui uma violação que, em última circunstância, destitui as pessoas de 
suas dignidades, deixando-as no patamar de homo sacer (Agamben, 2002). A privacidade é para Capurro a chave para resguardar o poder do indivíduo (Capurro, 2011, p. 13-41), e constitui a ferramenta com a qual ele exerce sua autonomia.

A privacidade é um direito determinante para a compreensão do indivíduo enquanto pessoa autônoma, com a qual é possível flexibilizar as assimetrias do poder, historicamente construído com a contribuição das muralhas e dos variados sistemas de vigilância, e construir sistemas mais harmônicos de segurança. A invasão à privacidade interfere no sentido de autonomia, vulnerabiliza e compromete os indivíduos em suas tomadas de decisão. Assume-se a dificuldade para encontrar hoje um lugar em que a intimidade não seja violada pelas organizações, empresas, Estados, etc. Estes se expandem com a abundante fonte de recursos que constituem a administração das necessidades e inseguranças humanas.

\section{Considerações finais}

A busca pela segurança não é imoral a priori. Ela corresponde à necessidade de proteção em nome da sobrevivência numa convivência em que as ameaças sejam recorrentes. Entretanto, o problema ético que daí decorre se avoluma quando a demanda por segurança se reduz à necessidade de defesa do próprio grupo. Tal fechamento funciona como alimentador da necessidade de demandas por vigilância e ao menos indiretamente favorece o crescimento das violências que geram as demandas. Nesse contexto, os condomínios, ao mesmo tempo em que respondem à necessidade real de espaços de segurança, dentro de metas éticas devem estar acompanhados por movimentos de conscientização crítica em favor de um ethos civilizacional no qual o pressuposto é o da segurança e paz, e não o pressuposto da constante necessidade de desconfiar e se proteger.

Uma contradição presente no ethos vigente é que mesmo conhecendo as razões profundas da insegurança, há também pouca predisposição para solucionar 
o problema. Como é próprio da cultura pós-moderna, a resposta na tentativa de solucionar o problema das violências é buscada individualmente e não coletivamente. Enquanto o indivíduo busca sua própria segurança, ao seu redor há um ambiente do qual ele depende e que é inseguro. Um modelo de segurança efetivo requer mudança no ethos social para que relações condominiais tenham características menos polarizadas pela necessidade de vigilâncias.

Ao final desta leitura bioética sobre a vigilância em condomínios, embora sejam reais e persistentes as necessidades de sistemas defensivos dos quais a vigilância faz parte, é indispensável sonhar com a utopia de uma casa comum, onde a diversidade dos grupos encontre formas de convivência em favor da segurança de todos. Em outras palavras Heidegger, ao falar sobre os fundamentos do "habitar hoje", diz que "a verdadeira crise na habitação reside no fato de que os mortais estão sempre procurando o ser da habitação e de que precisam, antes de tudo, aprender a habitar (Heidegger, 1979, p. 345-350). De fato, o acirramento da

necessidade de condomínios fechados por sistemas de vigilâncias passíveis de ambiguidades internas, como vimos, revela além de tudo o enorme déficit de uma sociedade que se imagina no topo desenvolvimento mas simplesmente não sabe conviver e habitar.

\section{REFERÊNCIAS}

AGAMBEN, Giorgio. Homo sacer: o poder soberano e a vida nua I. Belo Horizonte: Editora UFMG, 2002.

ARISTÓTELES. Política. Brasília: Editora Universidade de Brasília, 1997.

BAUMAN, Zygmunt. Vigilância Líquida: diálogos com David Lyon/Zygmunt Bauman. Rio de Janeiro: Editora Jorge Zahar, 2013.

BAUMAN, Zygmunt. Comunidade: a busca por segurança no mundo atual. Rio de Janeiro: Editora Jorge Zahar, 2003.

BENTHAM, Jeremy. O panóptico ou a casa de inspeção. Belo Horizonte: Editora Autêntica, 2000. 
BOÉTIE, Étienne de La. Discurso da Servidão Voluntária. São Paulo: Editora Brasiliense, 1999.

CAPURRO, Rafael; CAPURRO, Raquel. Secreto, lenguaje y memoria en la sociedad de la información. In: PIAZZA, Tommaso (Org.). Segredo e memória: ensaios sobre a era da informação. Porto-Portugal: Editora Afontamento, 2011, p. 13-41.

CORBIN, Alain. Os bastidores. In: PERROT, Michelle (Org.). História da vida privada 4: da Revolução Francesa à Primeira Guerra. São Paulo: Editora Companhia das Letras, 2009, p. 387 e 568.

DARWIN, Charles. A origem das espécies, no meio da seleção natural ou a luta pela existência na natureza. Porto-Portugal: Editora Lello \& Irmão, 2003.

DECLARAÇÃO Universal Sobre Bioética e Direitos Humanos. Tradução e Revisão: Cátedra UNESCO de Bioética da Universidade de Brasília, Editora Cátedra UNESCO de Bioética da Universidade de Brasília/Sociedade Brasileira de Bioética, 2005.

FOUCAULT, Michel. Vigiar e punir. Petrópolis-RJ: Editora Vozes, 2011.

FOUCAULT, Michel. Hermenêutica do Sujeito. São Paulo: Martins Fontes, 3a ed. 2010.

FOUCAULT, Michel. Microfísica do poder. Rio de Janeiro: Editora Graal, 1979, p. XXIII.

FRITZ JAHR; Paul Max. Bioética: uma revisão do relacionamento ético dos humanos em relação aos animais e plantas. Revista Kosmos, Stuttgart, n. 24, 1927, p. 21-32.

FUCHS, Christian. Como podemos definir vigilância? Revista Matrizes, São Paulo, ano 05, n. 1, jul/dez 2011, p. 109-136.

GARRAFA, Volnei; PORTO, Dora. Bioética, poder e injustiça: por uma ética de intervenção. In: GARRAFA, Volnei; PESSINI, Leo (Org.). Bioética: Poder e Injustiça. São Paulo: Editora Loyola, 2003, p. 35-44.

GILLES DELEUZE. Post-Scriptum sobre as Sociedades de Controle Conversações: 1972-1990. Rio de Janeiro: Editora 34, 1992, p. 219-226.

HEIDEGGER, Martin. Construir, habitar, pensar. In. CHOAY, Francoise (Org.). 0 urbanismo: utopias e realidades. São Paulo: Ed. Perspectiva, 1979, p. 345-350.

JONAS, Hans. O princípio responsabilidade. Rio de Janeiro: Editora PUC-RIO, 2006.

LARRÈRE, Catherine. Animalité. In MARZANO, Michela (org.) Dictionnaire de la Violence. Paris: PUF, 2011, p. 52-58.

LE GOFF, Jacques. O apogeu da cidade medieval. São Paulo: Editora Martins Fontes, 1992. 
LYON, David. Surveillance studies: an overview. Cambridge: Editor Polity, 2007.

MARQUESE, Rafael de Bivar. A dinâmica da Escravidão no Brasil: resistência, tráfico negreiro e alforrias, séculos XVII a XIX. Novos Estudos CEBRAP, São Paulo, n. 74, 2006, p. 107-123.

MATTÉI, Jean-François. A barbárie interior: ensaio sobre o i-mundo moderno. São Paulo: Editora UNESP, 2002.

MORIN, Edgar. Ciência com consciência. Rio de Janeiro: Editora Bertrand Brasil, 1999.

FREIRE, Paulo. Pedagogia do oprimido. Rio de Janeiro: Paz e Terra, 1990.

PLATÃO. As Leis. São Paulo: Editora Edipro, 1999, p. 302, Livro 08.

PLATÃO. A República. São Paulo: Editora Nova Cultural, 1997, Livros IV e V, (Os pensadores).

PROST, Antoine. Fronteiras e espaços privados. PROST, Antoine e VINCENT, Gérard. História da vida privada 5: da Primeira Guerra a nossos dias. São Paulo: Editora Companhia das Letras, 2009, p. 13-136.

ROLNIK, Raquel. O que é cidade. São Paulo: Editora Brasiliense, 2004.

ROUSSEAU, Jean-Jacques. Discurso sobre a origem e os fundamentos da desigualdade entre os homens. São Paulo: Editora Martins Fontes, 2005.

SIMMEL, George. A sociologia do segredo e das sociedades secretas. Tradução MALDONADO, Simone Carneiro. Revista Ciências Humanas EDUFSC, Florianópolis, vol. 43, n. 1, 2009, p. 219-242.

POTTER, Van Rensselaer. Global Bioethics: building on the Leopold legacy. East Lansing: Michigan State University Press, 1988.

VÁZQUEZ, Adolfo Sanchez. Ética. Barcelona: Editorial Crítica, 1978.

VEYNE, Paul. O Império Romano. In VEYNE, Paul. História da vida privada 1: do Império Romano ao ano mil. São Paulo: Editora Companhia das Letras, 2009, p. 17-211. 